\title{
COMPETENCIA ENTRE INSTITUCIONES MICROFINANCIERAS EN PERÚ, UNA MEDICIÓN CON EL INDICADOR DE BOONE PARA EL PERIODO 2003-2009*
}

Giovanna Aguilar Andía**

* doi: 10.11144/Javeriana.cao29-52.cimp. Este artículo es producto de la tesis doctoral “Dos estudios sobre las microfinanzas en el Perú". El artículo se recibió 02/03/2016 y se aprobó el 30/05/2016. Sugerencia de citación: Aguilar A., G. (2016). Competencia entre instituciones microfinancieras en Perú, una medición con el indicador de Boone para el periodo 2003-2009. Cuadernos de Administración, 29 (52), 169-198. http:// dx.doi.org/10.11144/Javeriana.cao29-52.cimp.

** Doctora en Economía de la Pontificia Universidad Católica del Perú, 2014, Lima, Perú. Profesora principal del Departamento de Economía de la Pontificia Universidad Católica del Perú, Lima, Perú.

Correo electrónico: gaguila@pucp.edu.pe 


\section{Competencia entre \\ instituciones \\ microfinancieras en Perú, una medición con el indicador de Boone para el periodo 2003-2009}

\section{RESUMEN}

Este artículo analiza la competencia entre instituciones microfinancieras (IMF) peruanas empleando el indicador de Boone de 2003 a 2009. Los hallazgos sugieren que las microfinanzas se han venido desarrollando en un entorno más competitivo, lo cual favorece la inclusión financiera y el desarrollo de instituciones eficientes. A su vez, pone en la agenda de las autoridades la responsabilidad de vigilar y evitar prácticas poco cuidadosas en la provisión de créditos que pueden conducir a sobreendeudamiento de los clientes con el deterioro de la cartera crediticia de las IMF. Se plantea para futuras investigaciones extender el periodo de análisis y/o estudiar la relación entre competencia, resultado financiero de las instituciones y endeudamiento de clientes.

Palabras clave: microfinanzas, competencia, indicador de Boone, microcrédito.

Clasificación JEL: G21, L19

Competition between microfinance institutions in Peru, a measurement using the Boone indicator in the period 2003-2009

\section{ABSTRACT}

This paper analyzes the competition between Peruvian microfinance institutions (MFIs) using the Boone indicator, from 2003 to 2009. The findings suggest that microfinance has been developing in a more competitive environment that promotes financial inclusion and the development of efficient institutions. In turn, it places on the authorities' agenda the responsibility for monitoring and preventing questionable practices in the provision of credit that can lead to over-indebtedness of clients with the deterioration of the loan portfolio of MFIs. For further research, it is suggested to extend the period of analysis and/or to study the relationship between competition, financial results of institutions and the level of indebtedness of customers.

Keywords: Microfinance, competition, Boone indicator, microcredit.

JEL Classification: $\mathrm{C}_{21}$, L19

\section{Concorrência} entre instituições microfinanceiras no

Peru: uma medição com 0 indicador de Boone para 0 período 2003-2009 das autoridades a responsabilidade de vigiar e evitar práticas pouco

\section{RESUMO}

Este artigo analisa a concorrência entre instituições microfinanceiras (IMF) peruanas empregando o indicador de Boone de 2003 a 2009. Os achados sugerem que as microfinanças vêm se desenvolvendo num contexto mais competitivo, o que favorece a inclusão financeira e o desenvolvimento de instituições eficientes. Por sua vez, coloca na agenda cuidadosas na provisão para créditos que podem levar a sobre-endividamento dos clientes com a deterioração da carteira creditícia das IMF. Propõe-se para futuras pesquisas estender o período de análise e/ou estudar a relação entre concorrência, resultado financeiro das instituições e endividamento de clientes.

Palavras-chave: microfinanças, concorrência, indicador de Boone, microcrédito. Classificação JEL: G21, L19 


\section{Introducción}

La industria regulada de microfinanzas en el Perú comprende las siguientes categorías de instituciones microfinancieras (IMF) ${ }^{1}$ : cajas municipales de ahorro y crédito (CMAC), cajas rurales de ahorro y crédito (CRAC), entidades de desarrollo de la pequeña y microempresa (EDPYME), así como bancos y financieras especializados en microfinanzas.

En la década de 2010 se ha tenido un entorno macroeconómico que ha favorecido la expansión de las microfinanzas peruanas ${ }^{2}$, igual efecto han surtido los cambios en la regulación. En efecto, a finales de 2002 la Superintendencia de Banca, Seguros y AFP (SBS) permitió que las CMAC abrieran oficinas la ciudad de Lima, lo que redujo barreras geográficas ${ }^{3}$ a sus operaciones y competencias. En 2008, se eliminó el esquema modular bajo el cual estaban reguladas las IMF, lo que permitió ampliar sus operaciones y servicios ${ }^{4}$ y operar en igualdad de condiciones regulatorias que otras entidades. En 2004 la SBS decidió mejorar la información de su central de riesgo compartida con las entidades del sistema financiero a fin de incentivar mejoras en la evaluación del riesgo de los clientes del sistema.

En 2007 la competencia en el mercado de microcréditos peruano también se vio favorecida por la llegada de la banca comercial al segmento microfinanciero (proceso llamado downscaling) a través de la compra de IMF, de larga y exitosa experiencia en este negocio. Asimismo, algunas EDPYME se transformaron en entidades de mayor tamaño y con más capacidades para actuar en el mercado microfinanciero (proceso llamado upgrading).

Un mayor nivel de competencia en la industria financiera tiene, por un lado, efectos positivos sobre el bienestar de los consumidores, a través de menores precios y mejores

1 Existen otras instituciones como las organizaciones no gubernamentales (ONG) con programas de microcrédito y las cooperativas de ahorro y crédito que también otorgan servicios financieros de pequeña escala, sin embargo, no se encuentran reguladas por la Superintendencia de Banca, Seguros y Administradoras de Fondos de Pensiones (SBS) y no poseen una significativa presencia en el mercado. Por lo tanto, no son sujetos de análisis en este estudio.

2 Entre el 2003 y el 2009 la tasa de crecimiento promedio anual del PIB peruano fue de 5,9\% mientras que la de las colocaciones de las IMF fue de $26 \%$ según información publicada por la SBS.

3 Resolución SBS 1276-2002 que aprobó las normas para que las instituciones de microfinanzas puedan acceder al mercado de Lima.

4 Decreto Legislativo 1028 de 2008 que modifica el artículo 290 de la Ley General 28677 Ley del Sistema Financiero y del Sistema de Seguros y Orgánica de la Superintendencia de Banca y Seguros. 
productos; y por otro, un impacto en la eficiencia de los intermediarios financieros (Bikker y Bos, 2005; Boone, 2008). Medidas convencionales de la competencia como el Índice de Herfindahl-Hirshman (IHH) o el Índice de Lerner no incorporan este último aspecto y por ello producen resultados no robustos (Boone, 2000, 2008). Por esta razón, el análisis y medición adecuados de la competencia entre instituciones financieras deben considerar posibles cambios en las firmas, principalmente referidas a sus niveles de eficiencia, tal como lo hace el indicador de Boone.

Este estudio analiza la competencia entre instituciones microfinancieras peruanas empleando el indicador de Boone con información de 2003 a 20095. Al estar basado en la relación entre la eficiencia de las firmas y su participación en el mercado el indicador de Boone, constituye una medida más robusta de la competencia respecto de otras medidas convencionales.

El análisis distingue los créditos otorgados a microempresas, llamados "créditos MES", de los otros tipos de créditos (consumo, comercial e hipotecario) los que son tratados como un solo producto crediticio llamado "créditos otros". Asimismo, en cada uno de estos mercados se identifican, siguiendo el criterio del valor del crédito promedio por deudor, subsegmentos de mercado y los tipos de IMF que en ellos compiten. Por tanto, el análisis se realiza por producto crediticio y subsegmentos de mercado.

La distinción entre "créditos MES" y los "créditos otros" se justifica por la importancia que tienen los primeros en la cartera de colocaciones de las IMF dada su orientación al financiamiento de actividades productivas y comerciales de micro y pequeñas empresas. Asimismo, el análisis de la competencia que identifica subsegmentos de mercados sejustifica dadas las diferencias en cuanto a escala de operaciones y clientes atendidos por las IMF.

Los resultados muestran que la competencia se ha intensificado en el mercado de "créditos MES". Sin embargo, en este mercado existen distintos niveles de competencia según el tipo de proveedores microfinancieros. Así, la competencia observada entre CRAC, financieras y EDPYME es mayor que la existente entre CMAC y bancos especializados. En el mercado de "créditos otros", se encuentra evidencia de que la competencia se ha intensificado entre CMAC y CRAC, no así entre bancos y financieras.

5 Los cambios en la metodología de clasificación de los créditos, realizados en el 2010 por la SBS, no permiten extender el periodo de análisis más allá de 2009. 
La principal contribución de este estudio es la aplicación de una medida robusta de competencia, como lo es el indicador de Boone, al análisis de la evolución de ésta en el mercado de microcréditos peruano durante un periodo de grandes cambios y transformaciones en la industria. Los resultados del estudio proporcionan elementos para la discusión y el debate futuros del tema de la competencia en la industria microfinanciera peruana.

Finalmente, los resultados sugieren que las microfinanzas en el Perú se han venido desarrollando en un entorno más competitivo, lo cual favorece la inclusión financiera, el desarrollo de instituciones eficientes $y$, a su vez, pone en la agenda de las autoridades involucradas con el sector, la responsabilidad de garantizar la continuidad del desarrollo de la competencia en condiciones favorables tanto para las IMF -evitando que incurran en malas prácticas o aumentos en la toma de riesgos-, como para los consumidores -evitando su sobreendeudamiento-.

El artículo se desarrolla de la siguiente manera: a continuación se presentan algunos hechos estilizados sobre las IMF y la competencia. Luego se expone el marco conceptual del estudio y la metodología empleada en el análisis. Se da paso a los resultados y su discusión y finalmente, se presentan las conclusiones y recomendaciones del estudio.

\section{Las IMF peruanas y la competencia}

A diciembre de 2009, las IMF fueron responsables de aproximadamente, el $10 \%$ del total de colocaciones del sistema financiero peruano. Al interior del sistema microfinanciero, las CMAC fueron responsables del $45 \%$ del total de colocaciones de este sector, seguidas por los bancos especializados con un 32\%. Las financieras y las CRAC colocan en conjunto el $18 \%$ mientras que las EDPYME colocaron tan solo el $5 \%$ del total de microcréditos $^{6}$.

Un aspecto relevante de la intermediación de las IMF es su orientación hacia el financiamiento de microempresas y de pequeños negocios. Los créditos a microempresas llegaron a representar más del 50\% del total de colocaciones de las IMF en el periodo 2003-2009. Los créditos comerciales elevaron su participación en el total de colocaciones, pasando del $12 \%$ en el año 2003 al 17\% en 2009, mientras que los créditos de consumo la han

6 Información publicada por la SBS (www.sbs.gob.pe). 
reducido del $31 \%$ en 2003 al $22 \%$ en 2009. La cartera hipotecaria tiene una reducida participación en el total de colocaciones de las IMF?

Esta información revela la importancia de los créditos a microempresas frente a otros tipos de crédito en la cartera crediticia y, por tanto, permite justificar la división de las colocaciones, para el análisis, entre dos tipos de crédito: créditos a microempresas, a los que llamaremos "créditos MES", y el resto de créditos, que agrega los créditos de consumo, comerciales e hipotecarios, a los que llamaremos "créditos otros".

\subsection{Subsegmentos de mercado por tipo de crédito}

León y Jopen (2011) dieron cuenta de la heterogeneidad en la demanda de microcréditos en el mercado peruano a partir de importantes diferencias encontradas en valor del crédito promedio por deudor estimado para cada tipo de IMF. Los créditos promedios por deudor de las CMAC y de los bancos son significativamente mayores a los de las EDPYME, financieras y CRAC. Este hallazgo revela que los clientes atendidos por CMAC y bancos especializados tienen distinto perfil de ingresos que los clientes servidos por las CRAC, EDPYME y financieras.

Bajo el supuesto de que el valor del crédito promedio por deudor está directamente correlacionado con el nivel de ingresos de los clientes, éste es de amplio uso para identificar la población atendida por las IMF en los estudios sobre alcance social de las microfinanzas (Christen, 2001; Schreiner, 2001). Dada la heterogeneidad en la demanda de microcréditos en el Perú, extendemos el uso del valor del crédito promedio por deudor, como criterio para para identificar las IMF que están orientadas a atender a clientes de similares niveles de ingreso tanto en el mercado de "créditos MES" como en el mercado de "créditos otros". De ahí que la competencia en cada uno de los mercados no sería entre todas las categorías de IMF sino que más bien ésta se produciría entre aquellas que están orientadas a atender a clientes con similares niveles de ingreso (crédito promedio), es decir, que en cada mercado se identifican subsegmentos de mercados atendidas por distintos tipos de IMF.

Tal como se muestra en la figura 1, en el mercado de "créditos MES", las CMAC y los bancos especializados presentan niveles de créditos promedio por deudor similares, en valor y con la misma tendencia. Por otra parte, los "créditos MES" promedio por deudor de las CRAC, financieras y EDPYME son de menor cuantía que los observados para CMAC y ban-

$7 \quad$ Información publicada por la SBS (www.sbs.gob.pe). 
cos. Según esta información, se distingue dos subsegmentos de clientes en el mercado de "créditos MES". El primero de ellos sería atendido por las CMAC y los bancos especializados, mientras que el segundo, lo sería por CRAC, financieras y EDPYME. Por tanto, la competencia en el mercado de "créditos MES" se daría de un lado, entre CMAC y bancos especializados por clientes de mayores ingresos $y$, de otro lado, entre CRAC, financieras y EDPYME por clientes con menores ingresos.

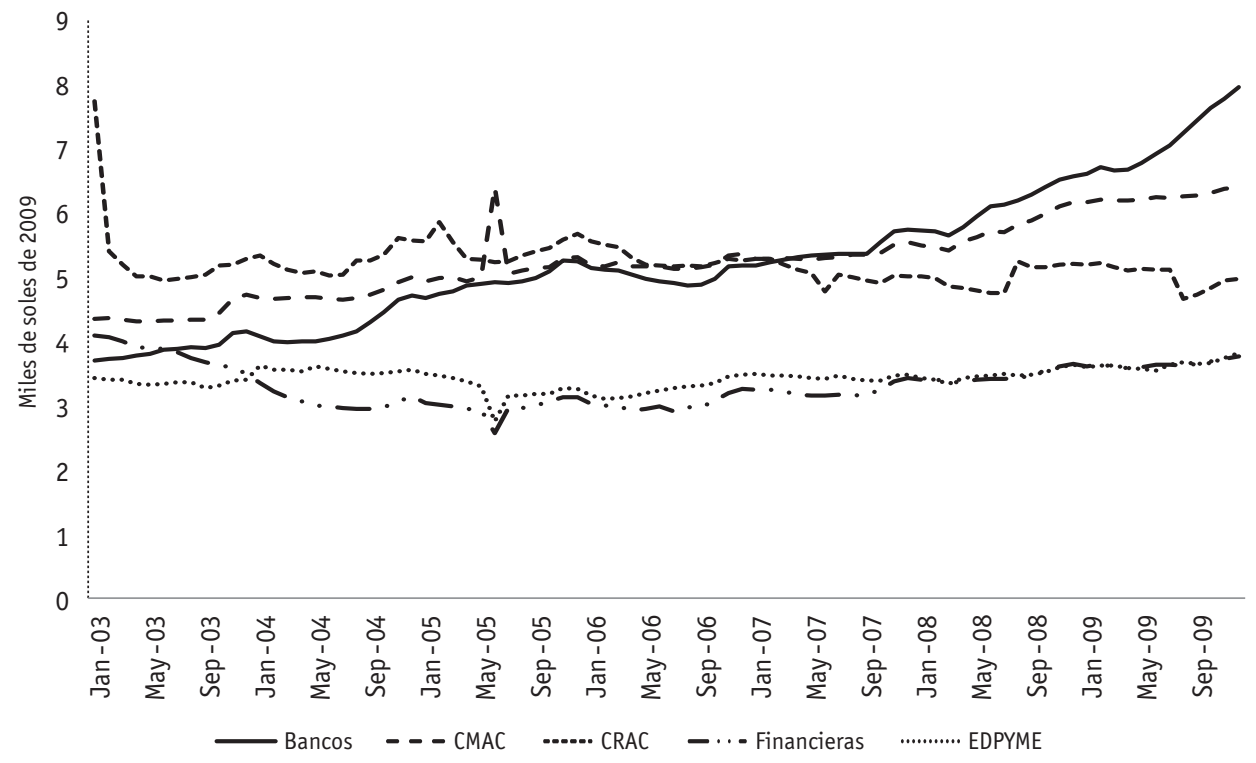

Figura 1. Créditos MES promedio por deudor

Fuente: elaboración propia con datos del sitio web de la SBS.

En la figura 2 se evidencia la similitud de los valores del crédito promedio "otros" para las CMAC, CRAC y EDPYME. Las financieras y los bancos especializados presentan créditos promedio de valores menores y similares entre sí. Por tanto, en el mercado de "créditos otros" también se observan dos submercados. En el primero competirían CMAC, CRAC y EDPYME, mientras que en el segundo lo harían bancos y financieras especializadas. Dada la reducida participación de los créditos de consumo, comerciales e hipotecarios en las colocaciones de las EDPYME ${ }^{8}$, a estas IMF solo se las considerará compitiendo en el mercado de "créditos MES".

8 En el año 2009, la cartera de créditos comerciales representó el 13\%; la de créditos hipotecarios, el 2\%; y la de créditos comerciales, el $10 \%$ de la cartera total de las EDPYME según información proporcionada por la SBS. 


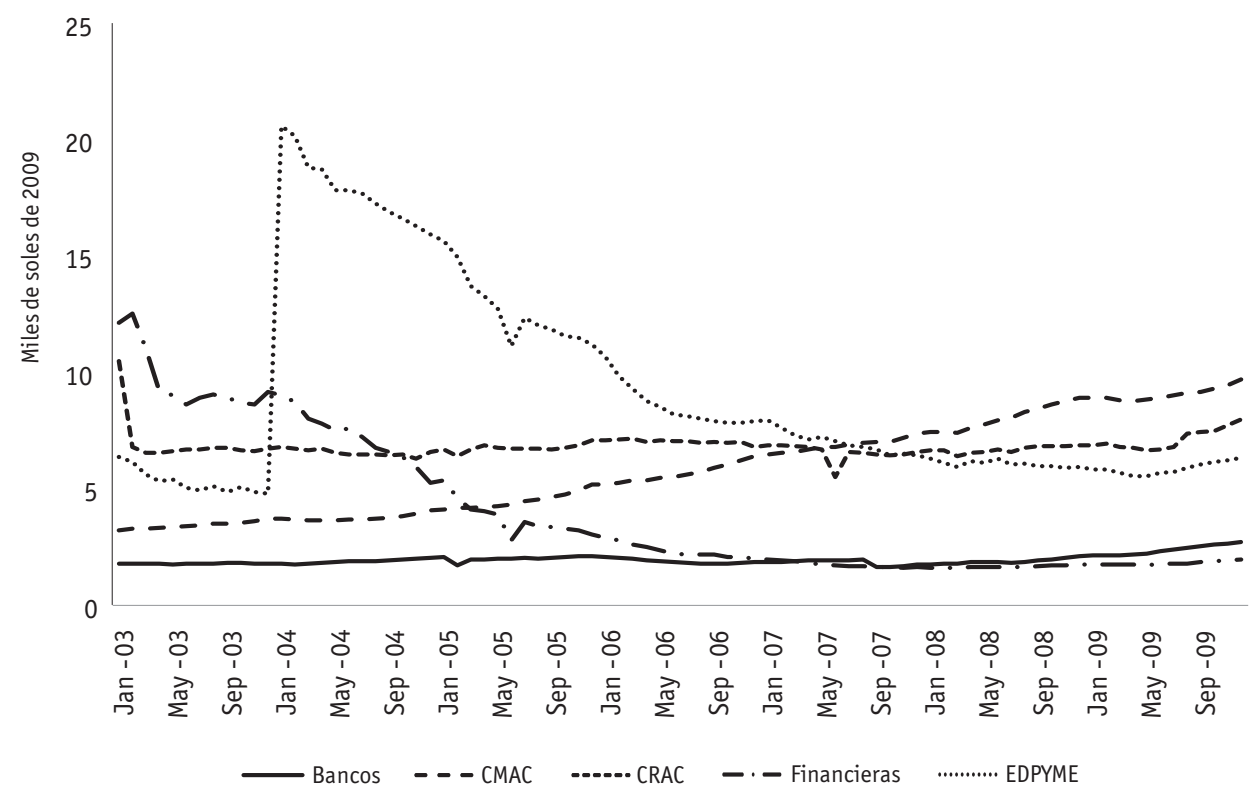

Figura 2. "Créditos otros" promedio por deudor

Fuente: elaboracición propia con datos de la SBS.

\subsection{Hechos estilizados sobre competencia}

Una mayor competencia en un mercado suele reflejarse en menores precios para los consumidores. En efecto, la evolución del spread de tasas de interés para el sistema microfinanciero de enero 2003 a diciembre 2009 muestra una tendencia decreciente, tal como puede observarse en la figura 3. Ello señala un entorno más competitivo para la actividad de intermediación microfinanciera.

Por otra parte, una reducción del ratio de rentabilidad patrimonial (ROE), tal como se muestra en la figura 4, es señal del mayor entorno competitivo que se configuró para la IMF en el periodo analizado.

Estos hechos estilizados muestran indicios de un aumento de la competencia entre las instituciones microfinancieras (IMF) peruanas en el periodo de estudio. 


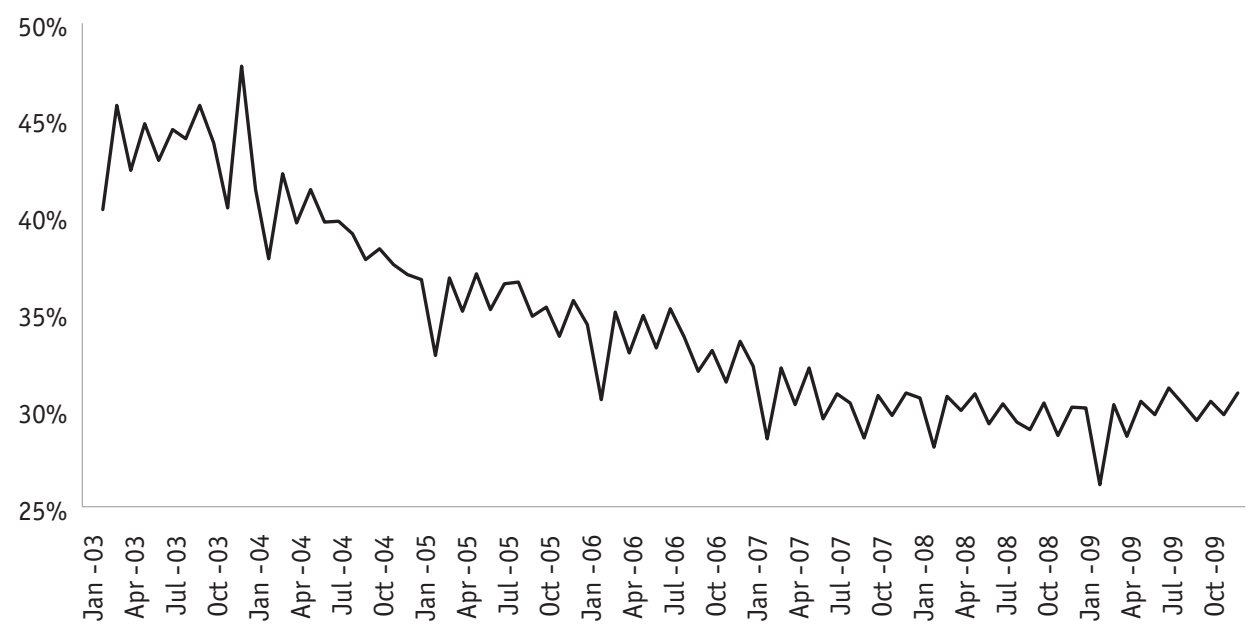

Figura 3. Sread de tasas de interés

Fuente: elaboración propia con datos de la SBS.

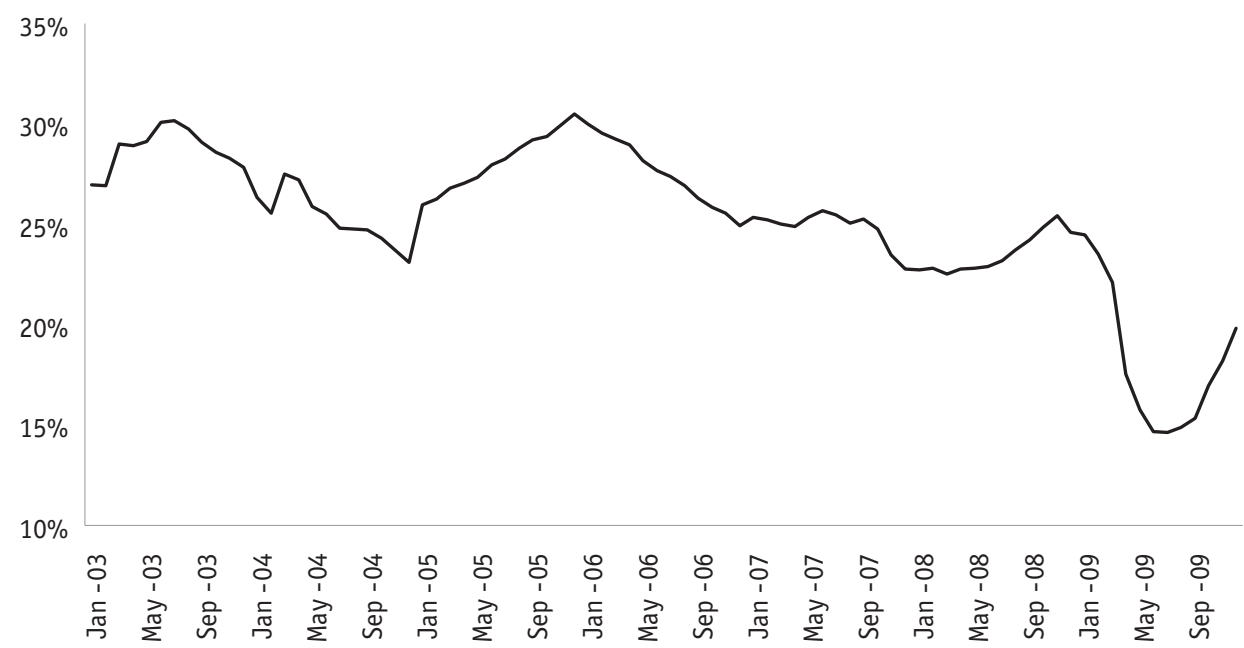

Figura 4. Rentabilidad patromonioal - ROE

Fuente: elaboración propia con datos de la SBS. 


\section{Marco conceptual}

\subsection{Medidas de competencia}

Varios enfoques teóricos se aproximan a los factores que determinan la competencia en un mercado (Claessen, 2009). Uno de ellos es el enfoque denominado Paradigma de Estructura-Conducta-Resultado (SCP por sus siglas en inglés), según el cual la estructura del mercado está referida a la concentración de mercado, la conducta al comportamiento de las firmas, es decir, si ésta es competitiva o colusiva en distintos aspectos (precios, elección de tecnología, publicidad, barreras a la entrada) mientras que los resultados están referidos a la eficiencia con la que opera el mercado.

Dos hipótesis sobre la relación entre la estructura de un mercado, la conducta de las firmas y de sus resultados, se derivan de este enfoque. La primera es la hipótesis de concentración-competencia, según la cual cuanto mayor es la concentración en el mercado menor es el nivel de competencia alcanzada ${ }^{9}$. La segunda hipótesis es la de eficiencia, según la cual la concentración en un mercado se relacionada directamente con la eficiencia de las firmas ${ }^{10}$.

En el contexto del paradigma de SCP, una medida de concentración y de competencia del mercado está dada por el Îndice de Concentración de Herfindahl - Hirschman (IHH) el que varía entre cero y uno. Cuanto más cercano de cero, evidencia una menor concentración (y por tanto mayor competencia) en el mercado, mientras que lo contrario, evidencia una mayor concentración (y menor competencia). Un problema del IHH es que solo cuantifica concentración, sin proporcionar información sobre la conducta de las firmas que origina dicha concentración. Un IHH que indique alta concentración puede ser indicio del funcionamiento de firmas muy eficientes compitiendo agresivamente entre sí, tal como lo establece la hipótesis de eficiencia. Esta ambigüedad inherente en la interpretación del IHH lo convierte en una medida poco apropiada para evaluar el nivel de competencia en un mercado.

La teoría de los mercados disputables o contestables (contestable markets) desarrollada por Baumol, Panzar y Willig (1982) establece que la estructura de mercado así como la

9 Las firmas con mayor participación en la industria pueden desarrollar una conducta colusiva y menos competitiva.

10 Las firmas más eficientes son las que sobreviven a la competencia produciéndose una mayor concentración del mercado. 
entrada y salida de firmas no son los factores más importantes para determinar el grado de competencia; en cambio, sí lo es el grado de disputabilidad. Es decir, es el grado de ausencia de barreras a la entrada y salida de firmas al mercado lo que hace posible que las firmas ya establecidas en el mercado desarrollen un comportamiento muy cercano al de competencia perfecta frente a la amenaza de entrada de nuevos competidores. Aun cuando este planteamiento suena razonable, muchas industrias del mundo real se caracterizan por presentar elevadas barreras de entrada, lo que se observa principalmente en la industria financiera, por lo que esta teoría de mercados contestables es poco útil para explicar el comportamiento competitivo en esta industria.

Los enfoques no estructuralistas ${ }^{11}$ proponen medidas de la competencia a partir de información de las propias firmas (ingresos y costos marginales) y del propio mercado (elasticidades) (Carbó y Rodríguez, 2007). De estos enfoques se derivan el estadístico H (Panzar y Rose, 1987) y el Índice de Lerner (IL) como indicadores de competencia. La dificultad de distinguir la intensidad de la competencia en un mercado a partir de los valores calculados para el estadístico $\mathrm{H}$ y de no incorporar adecuadamente las ganancias de eficiencia de las firmas en entornos más competitivos del IL (Boone, van Ours, van der Wiel, 2007) hacen que estas medidas de competencia sean limitadas para su análisis.

Boone $(2000,2008)$ desarrolló una nueva medida de la competencia basada en los beneficios de las firmas (que a su vez dependen de sus niveles de eficiencia) y que es más robusta teóricamente que el margen entre el precio y el costo marginal. El postulado central es que la competencia en un mercado mejora el desempeño de las firmas más eficientes (las de menor costo marginal) y deteriora el de las menos eficientes, lo que se traduce en un mayor beneficio para las más eficientes y menores beneficios para las menos eficientes. Van Leuvensteijn et al. (2011) introdujeron dos innovaciones en la aplicación del indicador de Boone al análisis de la competencia en el mercado bancario del área del euro. La primera fue el cálculo del costo marginal en lugar de aproximarlo mediante el costo variable ${ }^{12}$ mientras que la segunda fue el empleo de la participación de mercado de cada firma en lugar de los beneficios, dado que ésta también es consistente con la hipótesis de eficiencia. Por tanto, la relación entre el desempeño y la eficiencia de la firma queda establecida como:

$$
\ln s_{i}=\alpha+\beta \ln m c_{i}+\mu_{i}
$$

\footnotetext{
11 Denominados así porque sus argumentos no están basados en la estructura del mercado.

12 La forma de cálculo del costo marginal será explicada en la sección de la Metodología.
} 
Donde $s_{i}$ es la participación de mercado y $m c_{i}$ es el costo marginal de la firma $i$. En esta ecuación el parámetro de interés es el coeficiente $\beta$ (indicador de Boone). Cuanto más ineficiente la firma, mayor es su costo marginal, menor su beneficio y menor su participación en el mercado, por lo que el indicador de Boone es negativo. Y cuanto más negativo sea éste más intensa es la competencia, dado que es un escenario más competitivo, es el impacto de la ineficiencia sobre su participación en el mercado.

\subsection{Estado de la cuestión}

Van Leuvensteijn et al. (2011) fueron los primeros en aplicar el estimador de Boone al estudio de la industria bancaria en la zona euro. Oda y Silva (2010) lo emplearon para estudiar el nivel de competencia en el segmento de créditos de consumo del mercado bancario chileno.

En lo que respecta al caso peruano, no se registran estudios que empleen el indicador de Boone para analizar la competencia en el mercado financiero. Los trabajos encontrados utilizan otras metodologías para abordar el tema de la competencia. Por ejemplo, Cortez (2007) analizó la competencia en el sistema bancario sobre la base de la metodología de Panzar y Rose (1987), en el periodo 1995-2005. Aunque fue un estudio innovador, la conclusión a la que llega este estudio resulta muy general en un contexto en el que la banca comercial se caracteriza por ofrecer productos diferenciados. Morón et al. (2010) estudiaron la relación entre competencia y concentración en el sistema financiero peruano durante la última década estimando elasticidades de demanda para distintos tipos de créditos y depósitos. Concluyeron que la competencia aumentó el mercado de la mayoría de productos crediticios. Sin embargo, su análisis al agregar todas las instituciones financieras en un mismo mercado es poco conveniente para un mercado financiero como el peruano, caracterizado por una gran heterogeneidad de intermediarios financieros. Del Pozo (2008) también aplicó el enfoque de Panzar y Rose para estudiar el nivel de competencia en el sector microfinanciero peruano en el periodo 2003-2008. Sus estimaciones sugieren que el mercado microfinanciero peruano posee una estructura de competencia monopolística y que la competencia entre las instituciones microfinancieras aumentó.

\section{Metodología}

\subsection{Estimación de los costos marginales}

Los costos marginales, principales insumos para la estimación de la ecuación (1), se obtienen a partir de la estimación de la función de costos translogarítmica ${ }^{13}$ :

13 Para facilitar la presentación se han suprimido los subíndices de firma $(i)$ y tiempo $(t)$. 


$$
\begin{aligned}
\ln C T= & \alpha_{0}+\sum_{j} \beta_{j} \ln y_{j}+\sum_{m} \delta_{m} \ln p_{m}+\frac{1}{2} \sum_{j} \sum_{h} \beta_{j h} \ln y_{j} \ln y_{h}+\frac{1}{2} \sum_{m} \sum_{k} \delta_{m k} \ln p_{m} \ln p_{k}+\sum_{j} \sum_{m} \gamma_{j m} \ln y_{j} \ln p_{m}+\sum_{l} \phi_{l} z_{l}+ \\
& \frac{1}{2} \sum_{l} \sum_{q} \phi_{l q} z_{l} z_{q}+\sum_{l} \sum_{j} \eta_{l j} z_{l} \ln y_{j}+\sum_{l} \sum_{m} \varphi_{l m} z_{l} \ln p_{m}+v
\end{aligned}
$$

Donde CT representa el costo total de la firma, $y_{j}$ el producto crediticio j-ésimo de la firma, $\mathrm{p}_{\mathrm{m}}$ el precio del insumo m-ésimo, $z_{l}$ es la variable de control l-ésima (tasa de morosidad y tendencia) y v es un error aleatorio con media cero y varianza constante.

Las condiciones de homogeneidad lineal en el precio de los insumos (Gravelle y Rees, 2006) ${ }^{14}$ y el Teorema de Young (Mas-Colell, Whinston y Green, 1995) ${ }^{15}$ imponen las siguientes restricciones sobre los coeficientes de la ecuación (2):

$$
\begin{aligned}
& \sum_{m} \delta_{m}=1 \\
& \sum_{m}^{m} \delta_{m k}=0 \\
& \sum_{m}^{m} \gamma_{j m}=0 \\
& \sum_{m}^{m} \varphi_{l m}=0 \\
& \beta_{j h}=\beta_{h j} \\
& \delta_{m k}=\delta_{k m} \\
& \phi_{l q}=\phi_{q l}
\end{aligned}
$$

El costo marginal del producto $j$ se obtiene derivando la función de costo total respecto al producto $j$ :

$$
m c_{j}=\frac{\partial C T}{\partial y_{j}}=\frac{C T}{y_{j}}\left[\beta_{j}+\sum_{h} \beta_{j h} \ln y_{h}+\sum_{m} \gamma_{j m} \ln p_{m}+\sum_{l} \eta_{l j}\right]
$$

14 La propiedad de homogeneidad lineal en los precios de los factores productivos, de la función de costos garantiza que, ante un incremento los precios de todos los factores de producción en la misma proporción, los costos de producción de determinado nivel de producto, se incrementan en la misma proporción.

15 El Teorema de Young garantiza que se cumplan las condiciones de simetría de las segundas derivadas de la función de costos. Por ejemplo, $\beta_{12}=\beta_{21}$ implica que el efecto en los costos totales provocado por un cambio en el volumen producido del producto 1, y de éste sobre el volumen producido del producto 2, es idéntico al efecto que produce en los costos totales un cambio en el volumen producido del producto 2, y de éste sobre el volumen producido del producto 1 . Una interpretación similar puede hacerse para las otras restricciones de simetría. 
Para definir los productos e insumos empleados por las IMF en su actividad financiera, se emplea el enfoque de intermediación (Benston, Hanweck y Humphrey, 1982) según el cual, los intermediarios financieros son vistos como empresas que producen créditos a partir de la combinación de recursos prestables ${ }^{16}$, mano de obra e infraestructura física. Así, bajo este enfoque los costos totales de las entidades financieras incluyen los costos financieros además de los costos operativos y la producción se mide como el valor monetario de los distintos productos financieros ofrecidos.

Considerando dos productos crediticios: "créditos MES" y "créditos otros" y tres insumos: mano de obra, fondos prestables e infraestructura física (capital fijo), en términos de la notación de la ecuación (2) se tiene que: $\mathrm{y}_{1}$ : “créditos MES", $\mathrm{y}_{2}:$ "créditos otros", $\mathrm{p}_{1}$ : precio de mano de obra, $\mathrm{p}_{2}$ : precio de fondos prestables (costo financiero), $\mathrm{p}_{3}$ : precio del capital (costo de uso de la infraestructura física).

Dada la orientación de estas entidades crediticias a financiar las actividades productivas de microempresas y pequeños negocios, su cartera de crédito envuelve mayor riesgo, lo que implica mayores costos para su administración. Por este motivo, se introduce en la estimación de la función de costo la tasa de morosidad del total de créditos para controlar el costo del riesgo de la cartera de créditos de cada institución (Hartarska et al., 2013; Assefa et al., 2013).

Por otra parte, se espera que este progreso técnico reduzca los costos de producción. Así, introducimos una variable de tendencia en la función de costos a fin de recoger los efectos del cambio tecnológico (Hartarska et al., 2013; Assefa et al., 2013).

La función costo total presentada en la ecuación (2) fue estimada con información mensual para 42 IMF en el periodo enero 2003 - diciembre 2009 y para cada categoría de operadores microfinancieros. Dado que algunas IMF salen del mercado y otras entran, se trata de un panel no balanceado.

El cambio en la metodología de definición y clasificación de los créditos, que entró en vigencia en julio de 2010 no permite extender el periodo de análisis más allá de 2009. En efecto, la clasificación de créditos vigente hasta junio del año 2010 se basaba en la Resolución S.B.S. No 808-2003 según la cual la cartera de créditos de las instituciones

16 Los recursos prestables están constituidos por depósitos captados del público, líneas de crédito externas y capital propio. 
financieras se dividía en cuatro tipos: créditos comerciales, créditos a microempresas, créditos de consumo y créditos hipotecarios para vivienda. Según esta resolución, los créditos a microempresas estaban definidos como aquellos créditos directos o indirectos otorgados para el financiamiento de actividades de producción, comercio o prestación de servicios de personas naturales o jurídicas con un nivel de endeudamiento en el sistema financiero que no excediera de US $\$ 30.000$ o su equivalente en moneda nacional en el momento de otorgamiento el crédito. A partir de julio del año 2010, entra en vigencia la Resolución S.B.S. No 11356 2008, que modificó la definición y clasificación de los tipos de créditos de las entidades financieras. De esta manera a partir de julio de 2010 la cartera de créditos de las instituciones financieras es clasificada en ocho tipos de créditos: créditos corporativos, créditos a grandes empresas, créditos a medianas empresas, créditos a pequeñas empresas, créditos a microempresas, crédito de consumo revolvente, crédito de consumo no-revolvente y créditos hipotecarios para vivienda. Los créditos a microempresas según esta nueva clasificación fueron definidos como aquellos créditos destinados a financiar actividades de producción, comercialización o prestación de servicios, otorgados a personas naturales o jurídicas, cuyo endeudamiento total en el sistema financiero fuera no mayor a S/.20.000 durante los últimos seis meses. Por tanto, la serie de crédito MES antes de julio de 2010 es conceptualmente distinta a la publicada desde julio de 2010, lo que limita la extensión del análisis hasta una fecha más actual.

Las series que presentaron componentes estacionales fueron desestacionalizadas con el método X12 ARIMA. Las fuentes de datos son las estadísticas publicadas por la SBS, el Banco Central de Reserva del Perú (BCRP) y el Instituto Nacional de Estadística e Informática (INEI). Todas las variables monetarias están expresadas en soles de 2009.

\subsection{Estimación de los indicadores de Boone}

Los indicadores de Boone para cada año del periodo 2003-2009 se estiman a partir de la introducción de variables dicotómicas anuales que interactúan con los costos marginales en la ecuación (1), tal como se especifica, seguidamente:

$$
\ln s_{i t, j}=\alpha+\sum_{A=1}^{7} d_{A} \beta_{A} \ln m c_{i t, j}+\sum_{A=1}^{6} \theta_{A} d_{A}+\mu_{i t, j}
$$

Donde, $s_{i t, j}$ es la participación de la firma $i$ en el periodo $t$ en el mercado del crédito $j, m c_{i t}$ , es el costo marginal del crédito $j$ de la empresa $i$ en el periodo $t$.j=1,2 ("créditos MES" y "créditos otros") $, t=1,2, \ldots, 84, d_{A}$ es una variable dicotómica anual que toma el valor 1 
en el año $A$ y cero en caso contrario, siendo $A=1,2, \ldots, 7$ (2003 al 2009). De esta manera, en el contexto de la estimación con datos de panel es posible calcular indicadores de Boone variantes en el tiempo, específicamente, cambiantes en cada año del panel (van Leuvensteijn, 2011). Adicionalmente, con el propósito de controlar además posibles diferencias anuales se han introducido de manera aditiva las variables dicotómicas anuales y están representadas por el término $\sum_{A=1}^{6} \theta_{A} d_{A}{ }^{17}$. El término $\mu_{i j, t}$ es un error aleatorio con media cero y varianza constante. La tabla 1 describe los indicadores de las variables empleados en las estimaciones.

\section{Tabla 1}

Definición de variables e indicadores empleados en las estimaciones

\begin{tabular}{|c|c|}
\hline Variables & Definición \\
\hline \multicolumn{2}{|r|}{ Endógenas } \\
\hline Costo total (CT): & Costo operativo más gasto financiero \\
\hline Participación de mercado $\left(s_{j}\right)$ & $\begin{array}{l}\text { Participación de las colocaciones del producto crediticio j en total de } \\
\text { colocaciones del mercado. Donde } j=1,2 . \mathrm{s}_{1}=\text { participación de mercado de } \\
\text { "créditos } \mathrm{MES}^{\prime}, \mathrm{s}_{2}=\text { participación de mercado de "créditos otros" }\end{array}$ \\
\hline \multicolumn{2}{|l|}{ Exógenas } \\
\hline Producto crediticio $j\left(y_{j}\right)$ & Colocaciones. Donde $j=1,2 \cdot y_{1}=$ "créditos MES", $y_{2}=$ "créditos otros" \\
\hline Precio del insumo $m\left(p_{m}\right)$ & $\begin{array}{l}\text { Costo unitario de los insumos. Donde } \mathrm{m}=1,2,3 . p_{1}=\text { precio de la mano de } \\
\text { obra aproximado como los gastos en personal divididos por el total de } \\
\text { empleados de la institución, } p_{2}=\text { precio de los fondos prestables (costo } \\
\text { financiero) aproximado por la tasa implícita pagada por depósitos más } \\
\text { adeudos, } p_{3}=\text { precio de capital (costo de uso de la infraestructura física) } \\
\text { aproximado por la tasa pasiva de los depósitos a plazo fijo de un año } \\
\text { pagado por el sistema de CMAC }\end{array}$ \\
\hline Tasa de morosidad $\left(z_{1}\right)$ : & $\begin{array}{l}\text { Créditos en atraso y en cobranza judicial como porcentaje de los créditos } \\
\text { totales }\end{array}$ \\
\hline Tendencia $\left(z_{2}\right)$ & Tendencia lineal \\
\hline $\begin{array}{l}\text { Costo marginal del producto } j \\
\left(m c_{j}\right)\end{array}$ & $\begin{array}{l}\text { Costo marginal por producto. Donde } j=1,2 . m c_{1}=\text { costo marginal de } \\
\text { "créditos MES", } m c_{2}=\text { costo marginal de "créditos otros" }\end{array}$ \\
\hline
\end{tabular}

Fuente: elaboración propia con datos de la SBS.

La tabla 2 muestran los estadísticos descriptivos de los indicadores de las variables consideradas.

17 Este término contiene seis variables dicotómicas anuales. Por ejemplo $\mathrm{d}_{1}$ es una variable que adopta el valor de 1 cuando las observaciones corresponden al año 2003 y cero en caso contrario, $\theta_{1}$ es su respectivo coeficiente el que representa el efecto promedio del año 2003 sobre la participación de mercado promedio de las firmas. Una interpretación similar se da a los restantes coeficientes. 


\section{Tabla 2}

Estadísticas descriptivas

\begin{tabular}{|c|c|c|c|c|c|}
\hline Variable & Bancos & CMAC & CRAC & Financieras & EDPYME \\
\hline \multirow{2}{*}{$\begin{array}{l}\text { Costo total (miles de soles del } \\
\text { 2009) }\end{array}$} & $287.595,90$ & $56.506,57$ & $12.121,57$ & $42.197,86$ & $8.528,35$ \\
\hline & $(113.041,11)$ & $(44.856,34)$ & $(13.739,33)$ & $(36.350,25)$ & $(10.810,21)$ \\
\hline \multirow{2}{*}{$\begin{array}{l}\text { "créditos MES" (miles de soles } \\
\text { del 2009) }\end{array}$} & $735.919,50$ & $173.727,40$ & $32.644,38$ & $163.561,11$ & $27.507,08$ \\
\hline & $(551.239 .23)$ & $(148.555,65)$ & $(42.908,51)$ & $(145.311,25)$ & $(39.103,29)$ \\
\hline \multirow{2}{*}{$\begin{array}{l}\text { "créditos otros" (miles de soles } \\
\text { del 2009) }\end{array}$} & $526.780,10$ & $162.746,30$ & $29.361,59$ & $32.612,21$ & $10.816,59$ \\
\hline & $(268.560,12)$ & $(134.428,34)$ & $(34.321,65)$ & $(35.171,87)$ & $(21.034 .09)$ \\
\hline \multirow{2}{*}{ Precio de fondos prestables (\%) } & 6,46 & 7,67 & 7,13 & 9,40 & 9,45 \\
\hline & $(1,04)$ & $(1,98)$ & $(1,98)$ & $(1,74)$ & $(3,74)$ \\
\hline \multirow{2}{*}{ Precio del capital (\%) } & 8,31 & 8,31 & 8,36 & 8,31 & 8,31 \\
\hline & $(1,21)$ & $(1,21)$ & $(1,22)$ & $(1,23)$ & $(1,19)$ \\
\hline \multirow{2}{*}{$\begin{array}{l}\text { Precio de la mano de obra (miles } \\
\text { de soles del 2009) }\end{array}$} & 5,11 & 4,49 & 3,93 & 4,74 & 4,02 \\
\hline & $(1,05)$ & $(0,82)$ & $(1,03)$ & $(0,81)$ & $(0,83)$ \\
\hline \multirow{2}{*}{ Tasa de morosidad (\%) } & 4,04 & 5,11 & 8,71 & 4,36 & 7,80 \\
\hline & $(1,43)$ & $(1,59)$ & $(5,87)$ & $(1,18)$ & $(5,59)$ \\
\hline \multirow{2}{*}{$\begin{array}{l}\text { Participación de mercado de } \\
\text { "créditos MES" }(\%)\end{array}$} & 21,20 & 5,23 & 3,19 & 14,06 & 2,40 \\
\hline & $(0,07)$ & $(0,04)$ & $(0,03)$ & $(0,09)$ & $(0,02)$ \\
\hline \multirow{2}{*}{$\begin{array}{l}\text { Participación de mercado de } \\
\text { "créditos otros" (\%) }\end{array}$} & 46,40 & 7,63 & 1,54 & 2,49 & \\
\hline & $(0,19)$ & $(0,05)$ & $(0,02)$ & $(0,02)$ & \\
\hline \multirow{2}{*}{$\begin{array}{l}\text { Costo marginal de "créditos } \\
\text { MES"(miles de soles) }\end{array}$} & 0,24 & 0,16 & 0,18 & 0,19 & 0,27 \\
\hline & $(0,14)$ & $(0,06)$ & $(0,08)$ & $(0,04)$ & $(0,10)$ \\
\hline \multirow{2}{*}{$\begin{array}{l}\text { Costo marginal de "créditos } \\
\text { otros" (miles de soles) }\end{array}$} & 0,13 & 0,13 & 0,16 & 0,28 & \\
\hline & $(0,09)$ & $(0,03)$ & $(0,19)$ & $(0,16)$ & \\
\hline Número de observaciones & 180 & 979 & 1.107 & 270 & 814 \\
\hline
\end{tabular}

Nota: Los valores corresponden a la media y al desvío estándar (situado debajo y entre paréntesis)

Fuente: elaboración propia con datos de la SBS, el BCRP y el INEI.

\section{Resultados}

\subsection{Estimación de costos marginales}

La tabla 3 contiene las estimaciones de las funciones de costos totales para cada una de las cinco categorías de IMF. En cada caso, se estimó un modelo de efectos fijos de acuerdo con los resultados del test de Hausman y con errores robustos. 
Tabla 3

Estimaciones de la función de costo total por tipo de IMF

\begin{tabular}{|c|c|c|c|c|c|}
\hline Variable & CMAC & CRAC & Financieras & EDPYME & Bancos \\
\hline $\mathrm{y}_{1}$ & $\begin{array}{c}-1,44^{* *} \\
(0,42)\end{array}$ & $\begin{array}{l}1,28 * * \\
(0,35)\end{array}$ & $\begin{array}{c}4,62^{* *} \\
(1,75)\end{array}$ & $\begin{array}{c}-1,01 * * \\
(0,43)\end{array}$ & $\begin{array}{c}-17,16^{*} \\
(2,55)\end{array}$ \\
\hline $\mathrm{y}_{2}$ & $\begin{array}{l}2,89 * * \\
(0,46)\end{array}$ & $\begin{array}{l}0,88 * * \\
(0,30)\end{array}$ & $\begin{array}{l}1,90 * * \\
(0,66)\end{array}$ & $\begin{array}{c}0,60 * * \\
(0,16)\end{array}$ & $\begin{array}{c}8,05^{* *} \\
(1,41)\end{array}$ \\
\hline$p_{1}$ & $\begin{array}{l}-0,35 \\
(0,36)\end{array}$ & $\begin{array}{l}1,93 * * \\
(0,65)\end{array}$ & $\begin{array}{c}3,07 * * \\
(1,32)\end{array}$ & $\begin{array}{c}-3,62 * * \\
(0,68)\end{array}$ & $\begin{array}{c}1,06 \\
(1,20)\end{array}$ \\
\hline $\mathrm{p}_{2}$ & $\begin{array}{l}1,51 * * \\
(0,36)\end{array}$ & $\begin{array}{c}-2,56^{* *} \\
(0,63)\end{array}$ & $\begin{array}{c}3,34^{* *} \\
(1,14)\end{array}$ & $\begin{array}{c}0,37 \\
(0,47)\end{array}$ & $\begin{array}{c}-3,29 * * \\
(1,36)\end{array}$ \\
\hline$p_{3}$ & $\begin{array}{l}-0,16 \\
(0,49)\end{array}$ & $\begin{array}{l}1,63 * * \\
(0,55)\end{array}$ & $\begin{array}{c}-5,41 * * \\
(1,37)\end{array}$ & $\begin{array}{c}4,25 * * \\
(0,78)\end{array}$ & $\begin{array}{c}3,23^{* *} \\
(1,59)\end{array}$ \\
\hline $\mathrm{y}_{1} \mathrm{y}_{2}$ & $\begin{array}{c}-0,23 * * \\
(0,03)\end{array}$ & $\begin{array}{c}-0,06 * * \\
(0,03)\end{array}$ & $\begin{array}{c}-0,12 * * \\
(0,06)\end{array}$ & $\begin{array}{l}-0,02 \\
(0,02)\end{array}$ & $\begin{array}{c}0,02 \\
(0,09)\end{array}$ \\
\hline $\mathrm{y}_{1}^{2}$ & $\begin{array}{l}0,32 * * \\
(0,04)\end{array}$ & $\begin{array}{c}0,01 \\
(0,03)\end{array}$ & $\begin{array}{l}-0,28 \\
(0,18)\end{array}$ & $\begin{array}{l}0,15 * * \\
(0,05)\end{array}$ & $\begin{array}{c}1,33^{* *} \\
(0,18)\end{array}$ \\
\hline $\mathrm{y}_{2}^{2}$ & $\begin{array}{c}0,03 \\
(0,04)\end{array}$ & $\begin{array}{l}-0,02 \\
(0,03)\end{array}$ & $\begin{array}{l}-0,75 \\
(0,10)\end{array}$ & $\begin{array}{l}0,01 * * \\
(0,00)\end{array}$ & $\begin{array}{c}-0,63^{* *} \\
(0,10)\end{array}$ \\
\hline $\mathrm{p}_{1} \mathrm{p}_{2}$ & $\begin{array}{l}0,08^{*} \\
(0,05)\end{array}$ & $\begin{array}{l}0,24 * * \\
(0,07)\end{array}$ & $\begin{array}{l}-0,04 \\
(0,21)\end{array}$ & $\begin{array}{c}0,08 \\
(0,07)\end{array}$ & $\begin{array}{l}-0,10 \\
(0,20)\end{array}$ \\
\hline $\mathrm{p}_{1} \mathrm{p}_{3}$ & $\begin{array}{c}-0,20 * * \\
(0,09)\end{array}$ & $\begin{array}{c}-0,64^{* *} \\
(0,22)\end{array}$ & $\begin{array}{c}-0,49^{*} \\
(0,26)\end{array}$ & $\begin{array}{c}0,16 \\
(0,18)\end{array}$ & $\begin{array}{c}-0,44^{* *} \\
(0,21)\end{array}$ \\
\hline $\mathrm{p}_{2} \mathrm{p}_{3}$ & $\begin{array}{c}-0,35^{* *} \\
(0,06)\end{array}$ & $\begin{array}{l}-0,13 \\
(0,16)\end{array}$ & $\begin{array}{c}0,03 \\
(0,25)\end{array}$ & $\begin{array}{c}-0,57 * * \\
(0,12)\end{array}$ & $\begin{array}{l}-0,22 \\
(0,20)\end{array}$ \\
\hline $\mathrm{p}_{1}^{2}$ & $\begin{array}{l}0,09 * \\
(0,05)\end{array}$ & $\begin{array}{l}-0,06 \\
(0,07)\end{array}$ & $\begin{array}{c}-0,62 * * \\
(0,24)\end{array}$ & $\begin{array}{c}0,56 * * \\
(0,14)\end{array}$ & $\begin{array}{l}-0,05 \\
(0,13)\end{array}$ \\
\hline $\mathrm{p}_{2}^{2}$ & $\begin{array}{c}-0,12 \\
(0,09)\end{array}$ & $\begin{array}{l}0,28 * * \\
(0,08)\end{array}$ & $\begin{array}{c}-0,39 * * \\
(0,15)\end{array}$ & $\begin{array}{l}0,19 * * \\
(0,06)\end{array}$ & $\begin{array}{c}-1,15^{* *} \\
(0,49)\end{array}$ \\
\hline $\mathrm{p}_{3}^{2}$ & $\begin{array}{c}0,49 * * \\
(0,12)\end{array}$ & $\begin{array}{l}0,31 * * \\
(0,13)\end{array}$ & $\begin{array}{l}1,52^{* *} \\
(0,38)\end{array}$ & $\begin{array}{l}-0,41^{*} \\
(0,22)\end{array}$ & $\begin{array}{l}1,97^{* *} \\
(0,53)\end{array}$ \\
\hline $\mathrm{p}_{1} \mathrm{y}_{1}$ & $\begin{array}{c}0,06 \\
(0,04)\end{array}$ & $\begin{array}{c}-0,21 * * \\
(0,04)\end{array}$ & $\begin{array}{c}-0,17^{*} \\
(0,10)\end{array}$ & $\begin{array}{l}0,35 * * \\
(0,05)\end{array}$ & $\begin{array}{c}0,13 \\
(0,12)\end{array}$ \\
\hline $\mathrm{p}_{1} \mathrm{y}_{2}$ & $\begin{array}{l}-0,02 \\
(0,04)\end{array}$ & $\begin{array}{l}0,10 * * \\
(0,03)\end{array}$ & $\begin{array}{l}0,15^{*} \\
(0,08)\end{array}$ & $\begin{array}{c}-0,14^{* *} \\
(0,02)\end{array}$ & $\begin{array}{c}-0,13 \\
(0,09)\end{array}$ \\
\hline $\mathrm{p}_{2} \mathrm{y}_{1}$ & $\begin{array}{l}0,24^{* *} \\
(0,04)\end{array}$ & $\begin{array}{l}0,19 * * \\
(0,04)\end{array}$ & $\begin{array}{c}-0,23^{* *} \\
(0,09)\end{array}$ & $\begin{array}{l}0,07 \text { * } \\
(0,04)\end{array}$ & $\begin{array}{c}0,39 * * \\
(0,12)\end{array}$ \\
\hline $\mathrm{p}_{2} \mathrm{y}_{2}$ & $\begin{array}{c}-0,25 * * \\
(0,04)\end{array}$ & $\begin{array}{l}-0,01 \\
(0,04)\end{array}$ & $\begin{array}{c}0,03 \\
(0,08)\end{array}$ & $\begin{array}{c}0,02 \\
(0,02)\end{array}$ & $\begin{array}{c}0,10 \\
(0,14)\end{array}$ \\
\hline $\mathrm{p}_{3} \mathrm{y}_{1}$ & $\begin{array}{l}-0,01 \\
(0,07)\end{array}$ & $\begin{array}{l}-0,12^{*} \\
(0,06)\end{array}$ & $\begin{array}{c}0,30 * * \\
(0,12)\end{array}$ & $\begin{array}{c}-0,16^{* *} \\
(0,08)\end{array}$ & $\begin{array}{c}-0,48^{* *} \\
(0,13)\end{array}$ \\
\hline $\mathrm{p}_{3} \mathrm{y}_{2}$ & $\begin{array}{l}-0,01 \\
(0,08)\end{array}$ & $\begin{array}{c}0,04 \\
(0,05)\end{array}$ & $\begin{array}{l}-0,08 \\
(0,11)\end{array}$ & $\begin{array}{c}-0,14 * * \\
(0,06)\end{array}$ & $\begin{array}{l}-0,01 \\
(0,13)\end{array}$ \\
\hline
\end{tabular}




\begin{tabular}{|c|c|c|c|c|c|}
\hline Variable & CMAC & CRAC & Financieras & EDPYME & Bancos \\
\hline$z_{1}$ & $\begin{array}{l}-0,20 \\
(0,27)\end{array}$ & $\begin{array}{l}2,49 * * \\
(0,04)\end{array}$ & $\begin{array}{l}0,91 * \\
(0,51)\end{array}$ & $\begin{array}{l}1,70 * * \\
(0,44)\end{array}$ & $\begin{array}{c}-0,06 \\
1,23\end{array}$ \\
\hline $\mathrm{z}_{1}^{2}$ & $\begin{array}{l}0,14 * * \\
(0,05)\end{array}$ & $\begin{array}{c}-0,25^{*} \\
(0,04)\end{array}$ & $\begin{array}{c}0,10 \\
(0,10)\end{array}$ & $\begin{array}{l}0,19 * * \\
(0,07)\end{array}$ & $\begin{array}{c}0,03 \\
(0,11)\end{array}$ \\
\hline $\mathrm{z}_{1} \mathrm{y}_{1}$ & $\begin{array}{r}-0,001 \\
(0,03)\end{array}$ & $\begin{array}{c}-0,12 * * \\
(0,03)\end{array}$ & $\begin{array}{l}-0,03 \\
(0,07)\end{array}$ & $\begin{array}{c}0,20 * * \\
(0,04)\end{array}$ & $\begin{array}{l}0,31 * * \\
(0,09)\end{array}$ \\
\hline $\mathrm{z}_{1} \mathrm{y}_{2}$ & $\begin{array}{l}0,001 \\
(0,04)\end{array}$ & $\begin{array}{c}-0,07 * * \\
(0,02)\end{array}$ & $\begin{array}{l}-0,08 \\
(0,07)\end{array}$ & $\begin{array}{l}-0,02^{*} \\
(0,01)\end{array}$ & $\begin{array}{c}-0,28 * * \\
(0,06)\end{array}$ \\
\hline$z_{1} p_{1}$ & $\begin{array}{l}0,07^{*} \\
(0,04)\end{array}$ & $\begin{array}{l}-0,02 \\
(0,07)\end{array}$ & $\begin{array}{l}-0,09 \\
(0,11)\end{array}$ & $\begin{array}{c}0,02 \\
(0,09)\end{array}$ & $\begin{array}{c}0,18 \\
(0,12)\end{array}$ \\
\hline $\mathrm{z}_{1} \mathrm{p}_{2}$ & $\begin{array}{c}-0,14^{* *} \\
(0,04)\end{array}$ & $\begin{array}{l}0,14^{* *} \\
(0,05)\end{array}$ & $\begin{array}{c}-0,28 * * \\
(0,09)\end{array}$ & $\begin{array}{c}0,01 \\
(0,07)\end{array}$ & $\begin{array}{c}0,29 \\
(0,17)\end{array}$ \\
\hline$z_{1} p_{3}$ & $\begin{array}{c}0,07 \\
(0,05)\end{array}$ & $\begin{array}{l}-0,12^{*} \\
(0,07)\end{array}$ & $\begin{array}{c}0,37 * * \\
(0,11)\end{array}$ & $\begin{array}{l}-0,04 \\
(0,12)\end{array}$ & $\begin{array}{c}-0,46^{* *} \\
(0,17)\end{array}$ \\
\hline$z_{2}$ & $\begin{array}{c}-0,03 * * \\
(0,01)\end{array}$ & $\begin{array}{c}0,01 \\
(0,01)\end{array}$ & $\begin{array}{c}-0,15 * * \\
(0,05)\end{array}$ & $\begin{array}{c}0,06 \\
(0,01)\end{array}$ & $\begin{array}{c}0,15^{* *} \\
0,05\end{array}$ \\
\hline$z_{2}^{2}$ & $\begin{array}{c}0,00 \\
(0,00)\end{array}$ & $\begin{array}{c}0,00 \\
(0,00)\end{array}$ & $\begin{array}{c}-0,001^{* *} \\
(0,00)\end{array}$ & $\begin{array}{c}0,0003^{* *} \\
(0,00)\end{array}$ & $\begin{array}{c}0,00 \\
(0,00)\end{array}$ \\
\hline $\mathrm{z}_{2} \mathrm{y}_{1}$ & $\begin{array}{l}0,001^{*} \\
(0,00)\end{array}$ & $\begin{array}{c}-0,001 \\
(0,001)\end{array}$ & $\begin{array}{c}0,01 \\
(0,00)\end{array}$ & $\begin{array}{c}-0,005^{* *} \\
(0,00)\end{array}$ & $\begin{array}{l}-0,02 * * \\
(0,003)\end{array}$ \\
\hline$z_{2} y_{2}$ & $\begin{array}{l}0,001^{*} \\
(0,00)\end{array}$ & $\begin{array}{c}0,001 \\
(0,001)\end{array}$ & $\begin{array}{l}0,01^{* *} \\
(0,00)\end{array}$ & $\begin{array}{c}-0,001^{*} \\
(0,00)\end{array}$ & $\begin{array}{l}0,01^{* *} \\
(0,002)\end{array}$ \\
\hline$z_{2} p_{1}$ & $\begin{array}{r}-0,001 \\
(0,00)\end{array}$ & $\begin{array}{c}0,001 \\
(0,001)\end{array}$ & $\begin{array}{r}-0,004 \\
(0,00)\end{array}$ & $\begin{array}{l}-0,001 \\
(0,00)\end{array}$ & $\begin{array}{l}-0,001 \\
(0,002)\end{array}$ \\
\hline $\mathrm{z}_{2} \mathrm{p}_{2}$ & $\begin{array}{c}-0,002^{*} \\
(0,00)\end{array}$ & $\begin{array}{l}-0,001 \\
(0,001)\end{array}$ & $\begin{array}{c}0,01^{* *} \\
(0,00)\end{array}$ & $\begin{array}{l}-0,01^{* *} \\
(0,001)\end{array}$ & $\begin{array}{l}-0,01 * * \\
(0,003)\end{array}$ \\
\hline$z_{2} p_{3}$ & $\begin{array}{c}0,002^{* *} \\
(0,00)\end{array}$ & $\begin{array}{l}0,001 \\
0,001\end{array}$ & $\begin{array}{l}-0,004 \\
(0,00)\end{array}$ & $\begin{array}{l}0,01 * * \\
(0,003)\end{array}$ & $\begin{array}{l}0,01 * * \\
(0,003)\end{array}$ \\
\hline$z_{1} z_{2}$ & $\begin{array}{c}0,0002 \\
(0,00)\end{array}$ & $\begin{array}{c}-0,002^{* *} \\
(0,001)\end{array}$ & $\begin{array}{c}0,004^{*} \\
(0,00)\end{array}$ & $\begin{array}{l}-0,01 * * \\
(0,001)\end{array}$ & $\begin{array}{c}-0,004^{* *} \\
(0,002)\end{array}$ \\
\hline Constante & $\begin{array}{l}-0,23 \\
(3,10)\end{array}$ & $\begin{array}{c}-7,74 * * \\
(2,23)\end{array}$ & $\begin{array}{c}-26,37^{* *} \\
(9,00)\end{array}$ & $\begin{array}{l}5,54^{* *} \\
(2,05)\end{array}$ & $\begin{array}{l}6,64^{* *} \\
(1,88)\end{array}$ \\
\hline $\mathrm{R}^{2}$ & 0,98 & 0,95 & 0,99 & 0,94 & 0,99 \\
\hline $\begin{array}{l}\text { Test de } \\
\text { Hausman }\end{array}$ & $1.015,67$ & $1.151,46$ & 80,07 & 131,91 & 98,43 \\
\hline Prob Chi>2 & 0,00 & 0,00 & 0,00 & 0,00 & 0,00 \\
\hline
\end{tabular}

Nota: errores robustos entre paréntesis. ${ }^{*} p<0,1 .{ }^{* *} p<0,05$

Fuente: elaboración propia con datos de la SBS, el BCRP y el INEI.

La mayoría de los coeficientes estimados para las variables más importantes (productos y precios de insumos) son significativos y con los signos esperados. 
La morosidad incrementa los costos totales de las CRAC, las financieras y las EDPYME. Sin embargo, este resultado no se observa ni en las CMAC, ni en los bancos especializados. Este hallazgo está reflejando los altos costos asumidos por las CRAC, EDPYME y financieras a lo largo de su trayectoria como consecuencia de su orientación a servir a clientes del medio rural o de muy escasos recursos, clientes de mayor riesgo en el mercado microfinanciero.

El cambio tecnológico ha sido importante para reducir los costos totales solo en el caso de las CMAC y las financieras y no lo ha sido en el caso de las CRAC y las EDPYME. Un resultado sorprendente se encuentra para los bancos porque el coeficiente estimado para la tendencia tiene signo positivo y significativo.

La figura 5 presentan los costos marginales estimados de los "créditos MES" para bancos y CMAC. Los bancos por su parte experimentaron un comportamiento oscilante en el periodo analizado. El aumento sustantivo del nivel de costos marginales observado a inicios de 2009 puede ser explicado por los mayores costos enfrentados por el Banco del Trabajo en su proceso de conversión a Financiera Crediscotia a inicios de ese año. En relación a los costos marginales de los "créditos MES" de las CMAC, estos han presentado un comportamiento creciente a lo largo de todo el periodo.

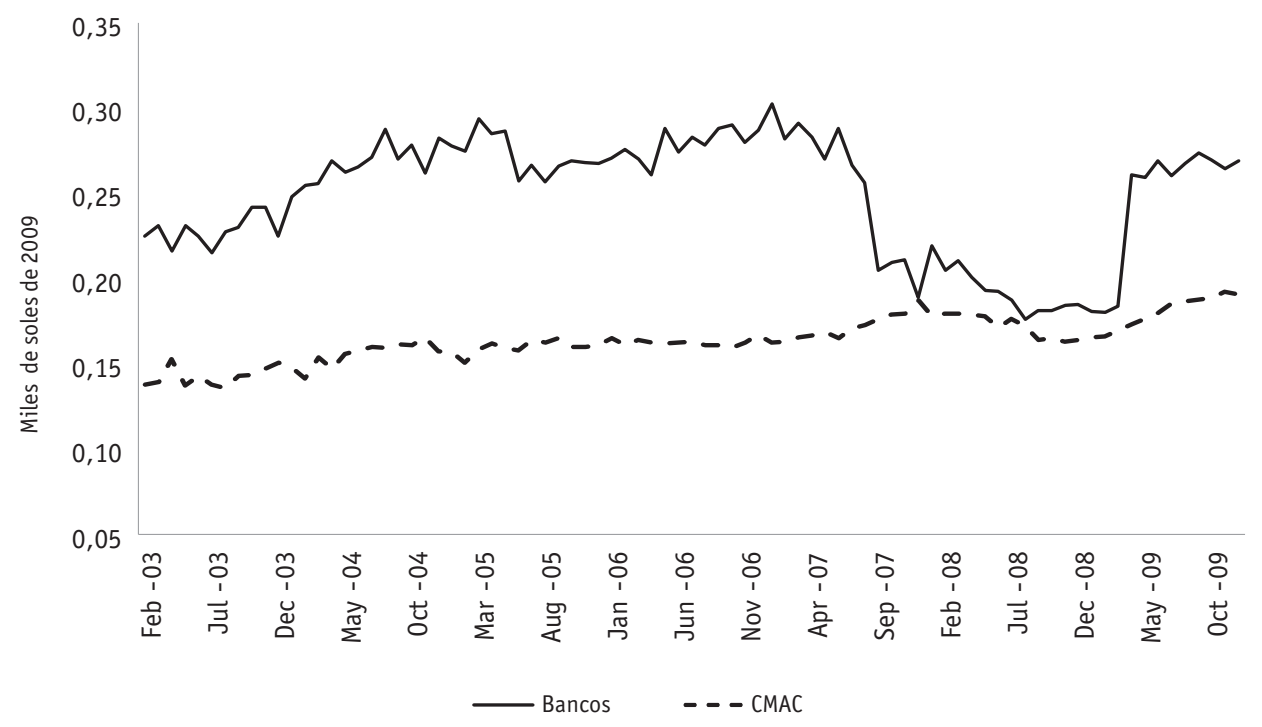

Figura 5. Costos marginales de "créditos MES" para bancos y CMAC

Fuente: elaboración propia con datos de la SBS, el BCRP y el INEI. 
La figura 6 presenta los costos marginales de los “créditos MES" de las financieras, CRAC y EDPYME. Tal como se observa, estos han decrecido en el periodo analizado, en el caso de las financieras y EDPYME siendo muy significativa esta reducción en el caso de estas últimas. Para las CRAC, el comportamiento de estos costos marginales ha mostrado una ligera tendencia al crecimiento hasta mediados de 2006, para luego iniciar un moderado recorrido decreciente.

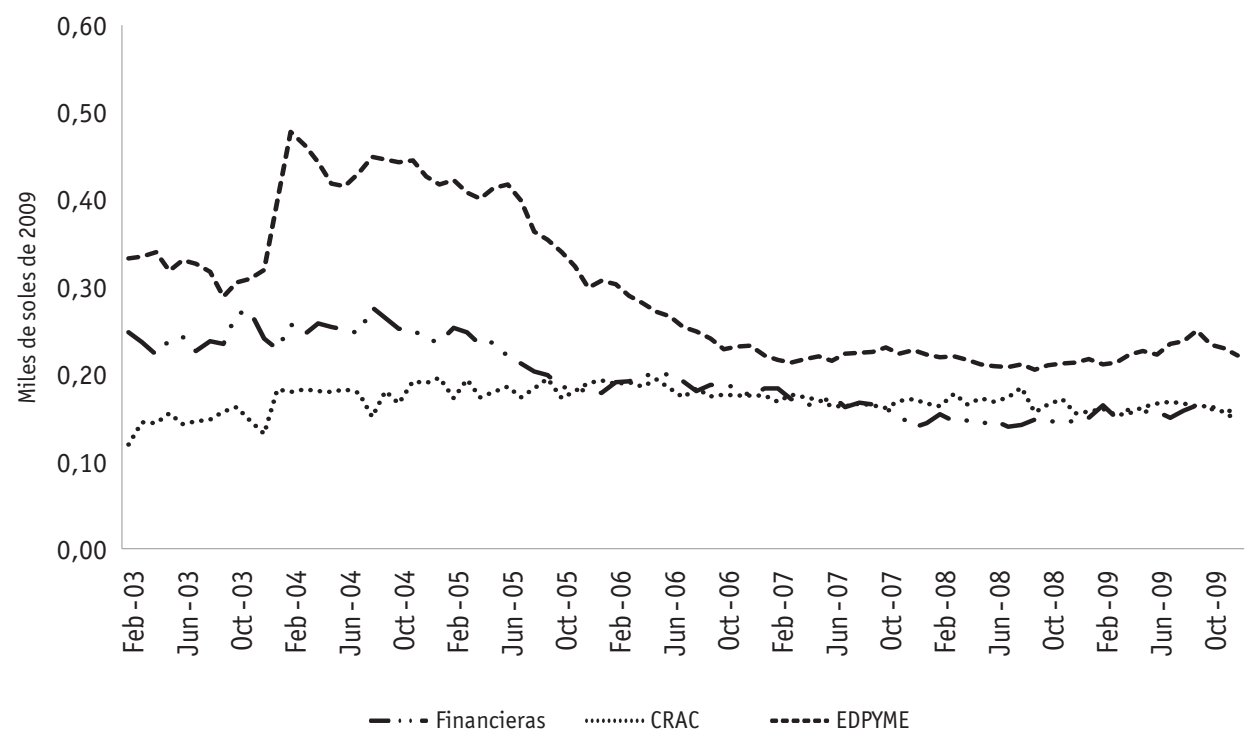

Figura 6. Costos marginales de "créditos otros" para financieras, CRAC y EDPYME

Fuente: elaboración propia con datos de la SBS, el BCRP y el INEI.

Los resultados sugieren que en un entorno más competitivo las IMF han obtenido diversos resultados en relación con las ganancias de eficiencia en la producción de créditos para microempresas. Mientras que las financieras y las EDPYME han presentado mejoras de eficiencia en la provisión de "créditos MES" a lo largo del periodo analizado, las CRAC presentan modestas mejoras de eficiencia. En el caso de los bancos, las ganancias de eficiencia para este tipo de créditos son reducidas, aparentemente, debido al cambio en la naturaleza de una de las entidades de este grupo de IMF. Por otra parte, las CMAC son el grupo de IMF para las cuales no se registra ganancias de eficiencia en términos de reducciones de los costos marginales asociados a los "créditos MES". 
Los costos marginales de los "créditos otros" de CMAC y CRAC se muestran en la figura 7. Como se aprecia, los costos marginales de las CMAC han seguido una tendencia decreciente mientras los de las CRAC han mostrado más bien una tendencia creciente que se revierte hacia el final del periodo.

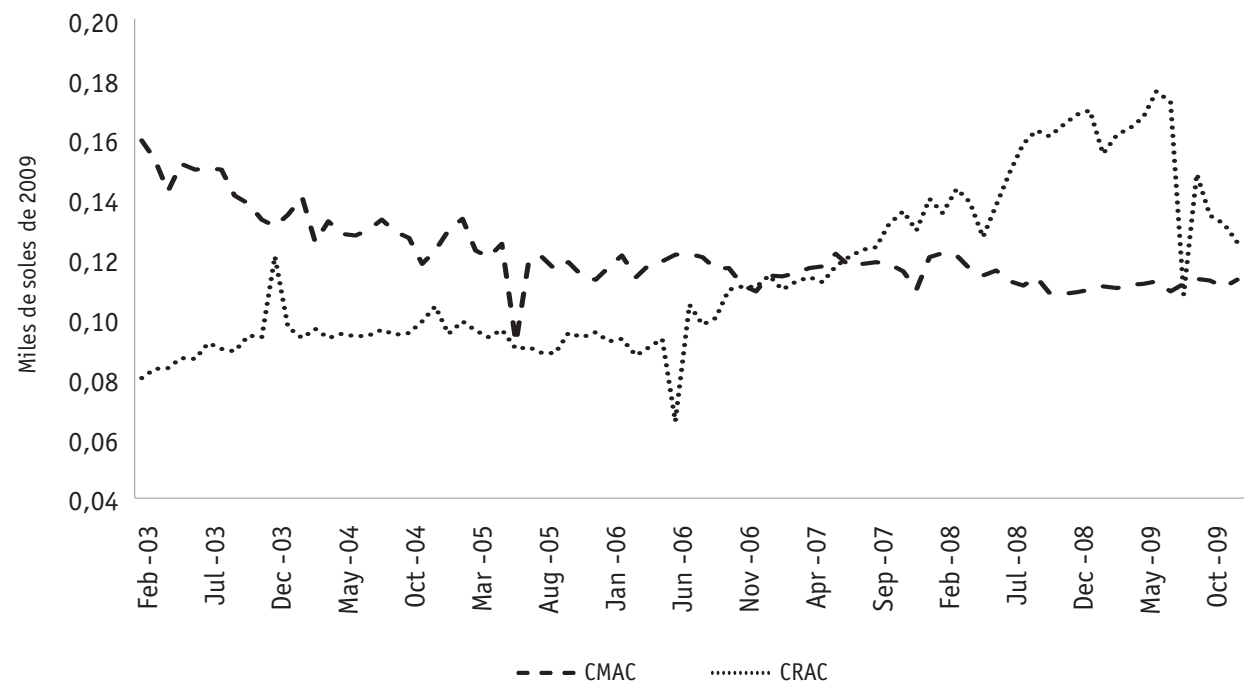

Figura 7. Costos marginales de "créditos otros" para CMAC y CRAC

Fuente: elaboración propia con datos de la SBS, el BCRP y el INEI.

Los costos marginales del "crédito otros" de los bancos muestran un comportamiento creciente hasta el primer trimestre de 2009. Luego de ello su tendencia es decreciente. En relación con la tendencia de los costos marginales de "créditos otros" de las financieras, esta se presenta creciente hasta el inicio de 2008 para luego iniciar una trayectoria descendente (ver figura 8).

Por lo mostrado aquí, tanto los bancos y las financieras especializadas como las CRAC han experimentado ganancias de eficiencia en la oferta de "créditos otros" hacia el final del periodo estudiado, mientras que en el caso de las CMAC las mejoras en eficiencia en la producción de este tipo de créditos se han observado en todo el periodo estudiado. 


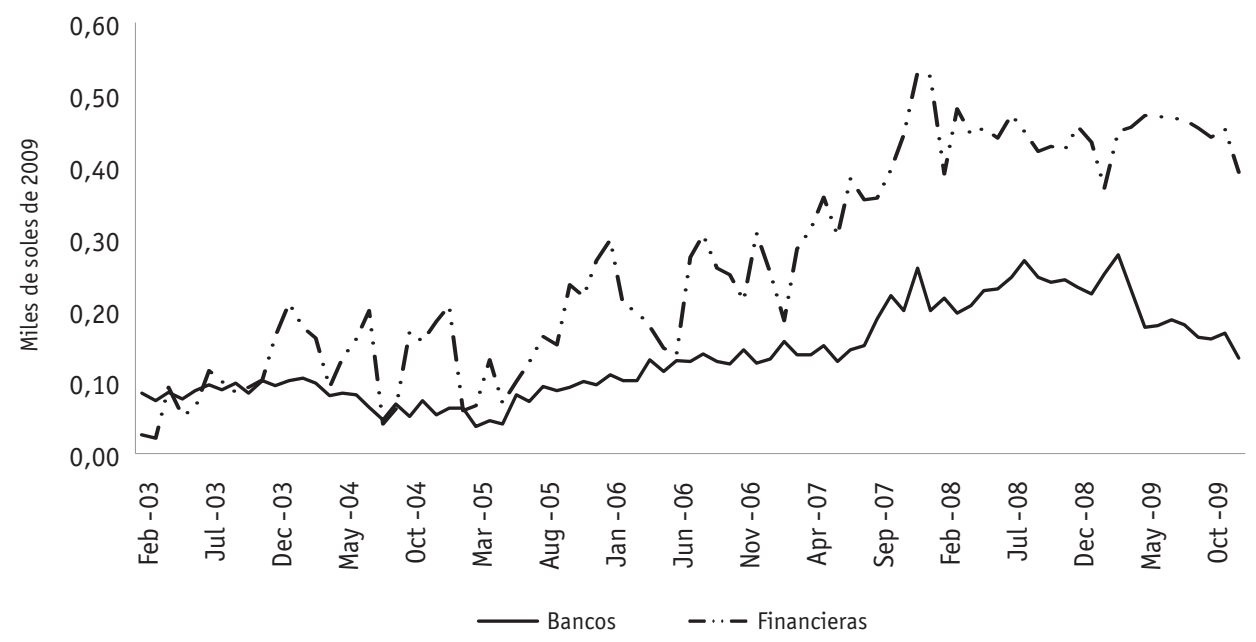

Figura 8. Costos marginales de "créditos otros" para bancos y financieras

Fuente: elaboración propia con datos de la SBS, el BCRP y el INEI.

\subsection{Estimaciones de indicadores de Boone}

\subsubsection{Mercado de "CrÉditos MES"}

La ecuación (4) fue estimada para el subsegmento de CMAC y bancos así como para el subsegmento de CRAC, financieras y EDPYME. En ambos casos, se estimó un modelo de efectos fijos, de acuerdo con los resultados del test de Hausman, con el método de Mínimos Cuadrados Generalizados Factibles (MCGF) a fin de corregir problemas de autocorrelación y heteroscedasticidad presentes en los residuos (Greene, 2012).

Como se aprecia en la segunda columna tabla 4, para el grupo de CMAC y bancos no todos los indicadores de Boone estimados para los años 2003 a 2009 son negativos como se esperaba ${ }^{18}$. Es a partir del año 2007 que los valores estimados se tornan negativos y solo en el 2009 se obtiene un valor negativo significativamente distinto de cero. Aun cuando la trayectoria seguida por los indicadores de Boone estimados para este mercado de "créditos MES" (donde compiten las CMAC y los bancos) no permite afirmar categórica-

18 Probablemente, este hallazgo esté vinculado al comportamiento creciente de los costos marginales de los “créditos MES" para ambas categorías de operadores microfinancieros entre los años 2003 y 2006 (ver la figura 5). 
mente que la competencia se ha incrementado durante todo el periodo analizado, sí es posible aseverar que hacia fines del periodo, se produjo un aumento de la competencia.

\section{Tabla 4}

Indicadores de Boone estimados para el mercado de "créditos MES"

\begin{tabular}{lcc}
\hline & CMAC y bancos & CRAC, financieras y EDPYME \\
\hline$\beta_{2003}$ & $0,05^{* *}$ & $-0,02$ \\
$\beta_{2004}$ & $0,08^{* *}$ & $-0,09^{* *}$ \\
$\beta_{2005}$ & $0,08^{* *}$ & $-0,09^{* *}$ \\
$\beta_{2006}$ & $0,05^{* *}$ & $-0,07^{* *}$ \\
$\beta_{2007}$ & $-0,004$ & $-0,20^{* *}$ \\
$\beta_{2008}$ & $-0,03$ & $-0,34^{* *}$ \\
$\beta_{2009}$ & $-0,07^{* *}$ & $-0,54^{* *}$ \\
Tets de Hausman & 266,49 & 44,1 \\
Prob Chi>2 & 0,00 & 0,00 \\
Número de observaciones & 1.079 & 1.949 \\
\hline
\end{tabular}

${ }^{*} p<0,05 .{ }^{*} p<0,1$

Fuente: elaboración propia con datos de la SBS, el BCRP y el INEI.

Este aumento tardío de la competencia entre CMAC y bancos por la provisión de "créditos MES" puede explicarse porque las presiones competitivas en este mercado se desarroLlaron hacia mediados de la década pasada con la llegada de las CMAC a Lima. Por ello, estas solo se reflejan en un indicador de Boone estadísticamente significativo hacia el final de la década.

A la luz de estos resultados, que muestran un incremento de la competencia entre estas dos categorías de IMF en el mercado de "créditos MES" hacia el final del periodo estimado, es conveniente que las autoridades económicas continúen promoviendo la igualdad de condiciones regulatorias para la competencia de las IMF con otras entidades del mercado. Asimismo, es igualmente importante que las autoridades se encuentren alertas para vigilar y evitar prácticas poco cuidadosas en la provisión de créditos, que pueden conducir a problemas de sobreendeudamiento de los clientes con el deterioro de la cartera crediticia de las IMF, a fin de garantizar el sano desarrollo de la competencia en la industria.

En el mercado de "créditos MES" donde actúan las CRAC, las EDPYME y las financieras, se encontró indicadores de Boone negativos y en su mayoría estadísticamente significativos, 
tal como se observa en la tercera columna de la tabla 4. Estos resultados sugieren un incremento significativo de la competencia en este subsegmento de mercado de "créditos MES".

Es importante notar cómo los indicadores de Boone se van tornando bastante más negativos hacia el final del periodo analizado, lo que confirma que la mayor competencia en este mercado, en efecto, está penalizando severamente a las firmas más ineficientes. Este resultado contrasta con el obtenido para el mercado de "créditos MES" donde compiten CMAC y bancos especializados, en el que si bien también existe evidencia de mayor competencia, ésta impone una menor pena a las firmas ineficientes ${ }^{19}$.

La entrada de la banca comercial al mercado microcrediticio así como el proceso de upgrading seguido por varias EDPYME también habrían sido factores que contribuyeron a elevar la competencia en este mercado.

En resumen, la evidencia encontrada revela un incremento importante de la competencia en el mercado de "créditos MES". Sin embargo, este mercado no es homogéneo y muestra distintos niveles de competencia según tipo de proveedores microfinancieros. Por tipo de instituciones, la competencia observada entre cajas rurales, financieras y EDPYME es mayor que la existente entre cajas municipales y bancos especializados.

\subsubsection{MERCADO de "CRÉditos otros"}

Las estimaciones de los indicadores de Boone para este mercado donde compiten las CMAC y las CRAC se obtuvieron mediante la estimación de la ecuación (4) a través de un modelo de efectos aleatorios. Se aplicó el método de MCGF para resolver problemas de autocorrelación y heteroscedasticidad detectados en los residuos.

Los valores estimados de los indicadores de Boone para el subsegmento de mercado de actuación de CMAC y CRAC se presentan en la segunda columna de la Tabla 5. Todas las estimaciones presentan los signos negativos esperados y son, en su mayoría, estadísticamente distintos de cero.

19 El indicador de Boone para el mercado donde compiten CMAC y bancos especializados en 2009 es de $-0,07$, mientras que para el mercado donde actúan las CRAC, financieras y EDPYME, es de -0,54. 


\section{Tabla 5}

Indicadores de Boone para el mercado de "créditos otros"

\begin{tabular}{lcc}
\hline & CMAC $y$ CRAC & Bancos y financieras \\
\hline$\beta_{2003}$ & $-0,01$ & 0,03 \\
$\beta_{2004}$ & $-0,02$ & $-0,01$ \\
$\beta_{2005}$ & $-0,02^{*}$ & 0,01 \\
$\beta_{2006}$ & $-0,03^{* *}$ & $-0,003$ \\
$\beta_{2007}$ & $-0,04^{* *}$ & $0,07^{* *}$ \\
$\beta_{2008}$ & $-0,06^{* *}$ & 0,02 \\
$\beta_{2009}$ & $-0,06^{* *}$ & 0,001 \\
Tets de Hausman & 2 & 149,27 \\
Prob Chi>2 & 0.99 & 0.00 \\
Número de observaciones & 1.857 & 415 \\
\hline
\end{tabular}

Fuente: elaboración propia con datos de la SBS, el BCRP y el INEI.

La trayectoria decreciente mostrada por el indicador de Boone en este submercado indica una intensificación de la competencia entre las CMAC y las CRAC por la colocación de un conjunto de créditos que incorpora créditos de consumo, comerciales e hipotecarios durante el periodo 2003-2009.

Estos hallazgos revelan que la competencia entre las CMAC y CRAC por proveer créditos de consumo, comerciales e hipotecarios se ha incrementado desde mediados de la década anterior.

Los indicadores de Boone para el segmento de mercado de "créditos otros" donde compiten bancos y financieras obtuvieron a partir de estimación de la ecuación (4) mediante un modelo de efectos fijos ${ }^{20}$ y con el método de MCGF para corregir problemas de autocorrelación y heteroscedasticidad de los residuos.

La tercera columna de la Tabla 5 muestra indicadores de Boone en su mayoría no significativos, con lo cual no se encuentra evidencia respecto de la evolución de la competencia en este submercado de "créditos otros" en el contexto de la racionalidad planteada por el indicador de Boone. Estos resultados no concluyentes llaman la atención al considerar

20 Según los resultados del test de Hausman. 
la reducción de costos marginales de este tipo de créditos tanto para los bancos como para las financieras (ver figura 8).

En función a los resultados hallados para el mercado de "créditos otros" se concluye que el aumento de la competencia solo ha sido significativo en el segmento donde compiten CMAC y CRAC, no habiendo evidencia concluyente sobre la evolución de la competencia entre bancos y financieras especializadas por la provisión de este tipo de créditos.

\section{Conclusiones}

La contribución de este estudio es el empleo de una medida robusta de competencia en el análisis de la competencia entre IMF peruanas en un periodo de importantes cambios en la regulación y transformaciones en la estructura de la industria.

El indicador de Boone es una medida de la competencia basada en la relación entre la eficiencia de las firmas y la participación de mercado. Establece que las firmas con menores costos marginales (más eficientes) consiguen mayor participación de mercado y, a medida que la competencia se incrementa, las firmas menos eficientes son más penalizadas con una menor participación de mercado. Esta medida de competencia es así más robusta que otras medidas convencionales como el $\mathrm{IHH}$, el Índice de Lerner o el estadístico H de Panzar y Rose, ya que consigue superar ambigüedades y dificultades conceptuales, derivadas de no tomar en cuenta el desarrollo de la eficiencia de las firmas en mercados con mayores niveles de competencia.

Este estudio analiza la competencia entre instituciones microfinancieras peruanas empleando el indicador de Boone, en el periodo 2003-2009. El análisis distingue los “créditos MES" de los otros tipos de créditos (consumo, comercial e hipotecario), los que son tratados como una sola categoría llamada "créditos otros". Asimismo, en cada uno de los mercados para estos dos productos crediticios se identificó, a partir del valor del crédito promedio por deudor, subsegmentos de mercado y las categorías de IMF que compiten al interior de cada uno de ellos. Así, en el mercado de "créditos MES" compiten, de un lado, CMAC y bancos especializados por atender a clientes de mayores ingresos y, de otro, lo hacen CRAC, EDPYME y financieras especializadas por clientes con menores ingresos.

En el mercado de "créditos otros" se identificaron también dos submercados. En el primero de ellos se encontrarían compitiendo las CMAC y las CRAC por atender a clientes 
de ingresos más altos mientras que en el segundo, competirían los bancos y financieras especializadas por atender a clientes con ingresos más bajos.

Los resultados muestran que la competencia aumentó en el mercado de "créditos MES". Sin embargo, este mercado muestra distintos niveles de competencia según tipo de proveedores microfinancieros. La competencia observada entre CRAC, financieras y EDPYME es mayor que la existente entre CMAC y bancos especializados. Más aun, la evidencia muestra que la competencia entre CMAC y bancos solo se intensifica hacia el final del periodo estudiado, lo que revela el desarrollo tardío de la competencia, por la provisión de créditos a microempresas, entre las entidades más grandes del mercado microcrediticio peruano.

La evidencia de mayor competencia en el mercado de "créditos MES" es consistente con las presiones competitivas generadas por varios procesos ocurridos a lo largo del periodo 2003-2009, como han sido la llegada de la banca comercial al mercado microcrediticio, el crecimiento y transformación - upgrading- de entidades como las EDPYME y la entrada de las CMAC al mercado limeño.

En el mercado de "créditos otros", la evidencia sugiere que la competencia entre CMAC y CRAC se ha incrementado significativamente, no encontrándose resultados concluyentes para la competencia entre bancos y financieras.

Los resultados sugieren que las microfinanzas en el Perú se han venido desarrollando en un entorno más competitivo. Así, este estudio pone en la agenda de discusión temas como el rol y la responsabilidad de las autoridades del sector financiero de garantizar el desarrollo de la competencia con medidas que resguarden el crecimiento saludable del sector y la igualdad de condiciones entre los operadores. Es importante considerar que, aunque nuestros resultados dan cuenta de que la competencia penaliza a las entidades menos eficientes, la intensificación de la competencia también podría llevar a resultados no deseados como el sobreendeudamiento de los clientes, el desarrollo de malas prácticas en el control y la gestión del riesgo por parte de las IMF, entre otros. Corresponde entonces la aplicación de medidas preventivas como la supervisión más estricta de los protocolos de evaluación de riesgo de los clientes por parte de las IMF, el fomento de la formación y utilización de centrales de riesgo que reduzcan la asimetría de información sobre los clientes, así como otras medidas.

Como futuras líneas de investigación derivadas del estudio, cabe mencionar el análisis de la relación entre la competencia y los resultados financieros de las entidades y el nivel de 
endeudamiento de clientes. Asimismo, la extensión del periodo de análisis constituye, en sí mismo, un tema en la agenda de investigación al ser la competencia un fenómeno dinámico de características cambiantes en el tiempo.

\section{Referencias}

Assefa, E.; N. Hermes, and A. Meesters. (2013). Competition and the performance of microfinance institutions. Applied Financial Economics, 23 (9), 767-782.

Baumol, W.; J. Panzar, and R. Willig. (1982). Contestable Markets and the Theory of Industrial Structure. San Diego, C.A: Hartcourt Brace Jovanovich.

Benston, G.; G. Hanweck, and D. Humphrey. (1982). Scale economies in banking: A restructuring and reassessment. Journal of money, credit and banking, 14 (4), 435-456.

Bikker, J., and J. Bos. (2005). Trends in competition and profitability in the banking industry: A basic framework. SUERF.

Boone, J. (2000). Competition. Discussion Paper Series No. 2636. London: Center for Economic Policy Research (CEPR).

Boone, J. (2008). A new way to measure competition. The Economic Journal, 118 (531), 1245-1261.

Boone, J.; J. van Ours, and H. van der Wiel (2007). How (not) to measure competition. Discussion Paper 32. Tilburg University, Center for Economic Research.

Carbó, S., and F. Rodríguez. (2007). The determinants of bank margins in european banking. Journal of Banking \& Finance, 31 (7), 2043-2063.

Christen, R. P. (2001). Commercialization and mission drift. Occasional paper No 5. Washington D.C.: CGAP.

Claessens, S. (2009). Competition in the financial sector: Overview of competition policies. Working Paper 09/45. Washington D.C.: IMF.

Cortez, G. (2007). Competencia Monopolística y Márgenes Bancarios en el Perú: 1995-2005. Pensamiento Crítico, 8, 115-130.

Del Pozo, C. (2008, noviembre). Nivel de Competencia en las Microfinanzas, Evidencia para el Perú. Documento presentado en el XXVI Encuentro de Economistas del Banco Central de Reserva del Perú, Lima, Perú.

Gravelle, H. y R. Ress. (2006). Microeconomía. Madrid: Pearson Educación.

Greene, W. (2012). Econometric analysis, 7 ed., Boston: Pearson.

Hartarska, V.; X. Shen, and R. Mersland. (2013). Scale economies and input price elasticities in microfinance institutions. Journal of Banking \& Finance, 37 (1), 118- 131.

León, J. y G. Jopen. (2011). La heterogeneidad del microcréditos en el sector financiero regulado peruano. En J. León y J. Iguiñiz (eds.) Desigualdad distributiva en el Perú: dimensiones (pp. 291-320. Lima: Fondo Editorial de la Pontificia Universidad Católica del Perú. 
Mas-Colell, A.; M. Whinston, and J. Green (1995). Microeconomic theory, vol. 1. New York: Oxford University Press.

Morón, E.; J. Tejada y A. Villacorta (2010). Competencia y Concentración en el Sistema Financiero Peruano. Documento de Discusión. Lima: Centro de Investigación de la Universidad del Pacífico.

Oda, D. y N. Silva. (2010). Competencia y toma de riesgo en el mercado de créditos de consumo bancario chileno, 1997-2009. Working Paper 562. Santiago de Chile: Banco Central de Chile.

Panzar, J., and J. Rosse. (1987). Testing for Monopoly Equilibrium. Journal of Industrial Economics, 35 (4), 229-263.

Schreiner, M. (2001). Seven aspects of loan size. Journal of Microfinance/ESR Review, 3 (2), 27-47.

Van Leuvensteijn, M.; J. Bikker, A. van Rixtel, and C. Sørensen. (2011). A new approach to measuring competition in the loan markets of the euro area. Applied Economics, 43 (23), 3155-3167. 